\title{
WAR INJURIES OF JAWS AND FACE.
}

\author{
By PERCIVAL P. COLE, F.R.C.S., L.D.S.
}

(Consulting Surgeon, Royal Cancer Hospital (Free); Surgeon Emeritus, Queen Mary's Hospital; Senior Surgeon, Seamen's Hospital and Tilbury Hospital; Surgeon, E.M.S.)

\section{Class of case.}

\section{Initial Considerations.}

The cases to be dealt with are those in which gross injury to the bony framework of the jaws is associated with soft tissue damage of varying degree.

It is not proposed to deal with the class of case that approximates to that which is met with in ordinary civil practice. In this class of case individual predilections will and can be exploited without jeopardizing the result. It might have been thought that the aim in view would be universally acknowledged were it not that opinion exists-shared, one hopes, by a small minority-that splinting in a large number of such cases is quite unnecessary. It is admitted that occlusion is not always satisfactory, but the capacity for adaptation on the part of the patient is invoked as a remedy. The patient must be trained, or train himself, to remedy the defects for which this mode of treatment is responsible.

In the severer injuries brought about by war conditions fundamental principles must be rigidly adhered to, and variation must be confined to questions of detail if consistent and satisfactory results are to be obtained.

\section{Segregation.}

This question was raised during the last war and answered in many ways. In the early days of the war and in areas where these cases were regarded as being general surgical cases, no segregation of any kind was adopted. The result was lamentable, for these patients were treated by surgeons without regard to their qualification to deal with them, or their interest in the particular lesions displayed. The services of the dental surgeon were not invoked until a late stage had been reached which robbed them of the value which earlier employment would have secured.

Elsewhere these war cases were relegated to the care of dental surgeons with little regard for the purely surgical problems involved.

Finally, segregation was adopted in such a way that all services were adequately represented and these cases were, quite rightly, classed in a separate category, the treatment for whom demanded from those in control special qualities and special training.

Segregation properly applied is beneficial in many ways. The patient is encouraged to persevere in what may be an arduous submission by the sight and company of others who have sustained equally, or possibly greater, damage and whose gradual rehabilitation can be observed.

Nursing, too, is facilitated by the adoption of a recognised routine and the inevitable. increase in skill that continued practice must confer. 
To those in control segregation is a time-saving and energy-saving measure. Cases are centralised and unnecessary dissipation of mental and physical output is obviated and the comparative value of alternative measures more easily assessed.

\section{Personnel and time of treatment.}

PERSONNEL. It must be recognised that the proper treatment of these cases can only be secured by invoking the combined efforts and pooled knowledge of the dental and surgical expert. That lesson was learned by bitter experience in the last war and it is to be hoped that the lesson has not been forgotten and will not have to be re-learned. Twenty years ago the dental surgeon confined himself to the technicalities of tooth conservation, tooth extraction, tooth regulation and the adaptation of prosthetic apparatus. He had no training in surgery in the special sense and in bulk he had no aspiration to indulge in it. With the advent of the operating stomatologist in recent years, conditions are now somewhat different.

A number of dental surgeons in the teaching schools and large centres of population practise surgery in the mouth to an extent which is not very clearly defined. Whereas in the last war measures that could be concerted by the dental surgeon and surgeon together may, to some extent, be undertaken by one person, combining in himself the abilities contributed then by joint partnership.

Even now, no extensive apprenticeship in general surgical methods has been served by more than a very few who can lay claim to be operating stomatologists. Certain it is that the planning and performance of operations on the soft parts, often of an intricate and extensive nature, will not be within the capacity evein of these few.

It will come about then that a large number of cases of the severer type with which we are now dealing will be treated by the operating stomatologist to the extent of his capacity and his efforts will be supplemented by those surgeons potentially or provedly capable of effecting reconstruction of the bony framework or of the soft tissues of the face and neck.

It is clear that unless care is taken to avoid it there will be inevitable overlap. Dental and surgical treatment cannot be recognised as separate or separable entities. It should be axiomatic that control from the beginning must be coincident and not consecutive whether the participating units are dental surgeon and surgeon or operating stomatologist and plastic surgeon.

The necessity of continuity has a bearing upon the site selected for treatment. Its importance was recognised during the last war and, as a result, the decision was made to treat these cases in institutions in this country and to abandon all idea of establishing stomatological centres abroad. Thus it came about that casualties were transhipped from France at the earliest possible moment and certainly by I9I6 were received in this country 24 to 36 hours after the infliction of their injuries.

Time of Treatment. Closely associated with this question of personnel, in fact inseparable from it, is the time factor in the matter of treatment. Continuity must be established from the very earliest time and be of such a nature as will safeguard the interests of the patient not only by knowing what to do, but by kncwing what not to do.

The concensus of opinion arrived at by experience during the last war was that splinting should be undertaken as early as possible. Early reduction and retention 
of fragments in jaw injuries far from being disadvantageous are effectual means of combating sepsis and add materially to the comfort and well-being of the patient. It is difficult to exaggerate the importance of this question, for misconceptions regarding it have been, and possibly will be, responsible for much suffering and much intervention that might be avoided. Until cases were promptly transferred to this country in the last war splinting was delayed because of its supposedly harmful consequences, with the result that in the earlier days of the war the greater part of the sum total of endeavour devoted to this type of war injury was centred not upon the treatment of fractures but upon the treatment of neglected fractures.

\section{Scope of immediate intervention (primary suture in relation to function).}

It will be accepted as a truism that in these cases functional must take precedence of cosmetic considerations. Bony lesions must, therefore, be dealt with first in such a way as to make possible the restoration of normal function.

It may be laid down as an axiom that the repair of damaged or destroyed soft parts should never be undertaken until fractured fragments have been efficiently splinted. Such an easily effected measure as inter-dental wiring to these serious lesions is usually not applicable except as a purely temporary expedient. The adaptation of efficient splints requires special apparatus, special equipment and special personnel. The attachment of these to a casualty clearing station is impracticable.

The primary suture of wounds must be undertaken within a few hours if success is to be attained. In the circumstances the two measures are clearly incompatible. For the maximum of success to be obtained by primary suture the wound should be clean-cut, and without loss of tissue, either originally determined or compelled by the necessity to trim wound edges. Briefly put, conditions must be such that access to the mouth will not be restricted as the result of immediate action or future behaviour. Wounds associated with damage to the bony structure of the jaws are so commonly complicated by contusion, laceration and actual loss of tissue that these favourable conditions will rarely be met.

Broadly speaking, primary suture in cases associated with bony lesions is not to be recommended. 'Well-meaning but mistaken interference in this direction was responsible in the early stages of the last war for a great deal of unnecessary trouble and suffering. As I have myself recorded, insertion of any form of splint was in many such cases impossible without resort to surgical measures.

In connection with this question of primary suture arises the whole question of the amount and nature of the first aid intervention that is admissible. The so-called "cleaning-up" operation was a bugbear in the early days of the last war. Teeth were extracted, bony fragments removed, soft parts sutured without attempt to control fractured fragments, with the result that obstinate trismus, due to cicatricial contraction, gross degrees of mal-union and a quite unjustifiable number of cases of non-union arose. These cases should be transferred to the care in continuity of effective personnel, at the earliest possible moment with the least possible interference. This question is particularly stressed because there is some evidence that the old fallacies may be perpetuated to conform to some academic ritual in an endeavour to bring the treatment of these wounds into line with that of wounds in general. We may be assured that no intelligent surgeon would do this or that, but in fact this and that has been done by surgeons, reflection on whose intelligence would be instantly and rightly resented. 
To prevent the formation of unnecessary cicatricial tissue by the elimination of suppuration, skin should be tacked to mucous membrane across exposed raw surfaces which they limit. Prior to transfer to expert control, this will be the only intervention that can suitably be undertaken in the majority of cases.

\section{Toilet of the mouth.}

\section{The Course of Treatment.}

Both before and after the necessary splints have been adapted, provision for cleansing the mouth must be made. In the class of case under discussion it is usually impossible for the patient to maintain his mouth in a condition of cleanliness by the use of mouth washes. The mechanism whereby fluids may be distributed in a manner forceful enough to wash away food débris and possibly purulent derivatives from the tissues involved will almost certainly be either completely lost or reduced to such an extent as to be inadequate. It comes about, therefore, that supplementary mechanical methods must be adopted and these will all involve the use of pressure, no matter how applied.

Pressure can be exerted hydrostatically from a reservoir of irrigating fluid suspended at a sufficient height. The same mechanism of pressure applied by means of Higginson's syringe or the same principle effected by means of an atomiser (C.O.2 sparklet) have their claims. Of these methods I prefer irrigation from a suspended reservoir. Efficacy depends more upon the mass of fluid employed than upon its nature. The choice of fluid will vary but I have employed in these cases lot. sod. chlorinat. of the British Pharmacopoia and another favourite used in the last war was chloramine $T$ in the strength of $\frac{1}{2}$ to I per cent. solution.

In addition to massive irrigation many of these patients are able to keep their splints clean and bright by the use of a soft tooth brush. The moral effect of this active participation in their treatment is of considerable value and serves to establish a bond between the patient and the professional control, which compels a co-operative attitude and eases the difficulties that arise in the course of prolonged treatment which may test the endurance of all parties concerned.

\section{Nutrition.}

Feeding may present nursing problems of considerable difficulty and importance. In the early stages there will be, added to difficulty of access, reluctance on the part of the patient to be fed, occasioned either by reaction to inconvenience or by a distaste brought about by his physical condition.

Fluids may require to be administered by feeding-cup with tube attached.

Nasal feeding will be required in some cases and gastrostomy will occasionally be advisable to overcome difficulties that cannot be met otherwise.

Maintenance of weight will be an effective check upon the efficacy of feeding methods and materials and in severe cases calorie charts whereon the daily intake is indicated should be used as is done in modern radium clinics for cases of cancer involving the mouth, larynx and pharynx.

\section{Procedure to existing teeth.}

Conflicting views have been expressed on this question. In dental circles removal of all septic teeth and roots and all teeth in the line of fracture is freely advocated as a routine and necessary preliminary to any form of treatment. It. 
is not without significance that this clear cut advocacy is repudiated by the admission that it is extremely important to retain a tooth in the posterior fragment for splinting purposes and the benefit of retaining it even for a time outweighs the septic risks of keeping it. The control of the posterior fragment has been and will be a major problem and the retention of any and every relevant means is thoroughly justified.

The description "septic" applied to teeth can be very comprehensive. It is pertinent to ask what is a septic tooth for the purpose in view; whether the conditions that would warrant its extraction as a possible source of focal sepsis are here applicable, and if not, at what particular stage in its decline from grace its removal becomes immediately imperative.

Comminution is common and in many cases, therefore, the line of fracture will be shown radiographically to involve several teeth whose sacrifice is demanded immediately on this evidence alone. It is certain that in such cases as also where in simpler fractures a single tooth is similarly placed extraction will frequently not be necessary even as an ultimate resort. Experience teaches that discriminating conservatism can be exercised not only with safety, but with advantage.

The task of reduction, retention and immobilisation of fractured fragments is rendered much easier when teeth are present to serve as natural abutments. Convincing reason must be shown to justify the removal of natural features which can be turned to such good account. Retention in any situation is advocated when a tooth or teeth can assist the operator to attain a result which their sacrifice would make impossible, or, at any rate, problematical.

A further point in favour of immediate conservatism is the fact that early removal of teeth in the neighbourhood of a fracture is, owing to rapid absorption of the alveolus, a frequent cause of the lacerated soft tissues becoming adherent to a more extensive area of bone and thus rendering more difficult the subsequent adaptation of a denture. In other words, encroachment is made upon the depth and elasticity of the buccal sulcus.

\section{Occlusion versus Union.}

During the last war the attainment of union was placed first by some authorities. Teeth were extracted to allow a posterior fragment to come forward or their sacrifice was undertaken at a later date for the reason that their function as a masticating mechanism had been seriously diminished. This attitude was more pronounced at the beginning of the war at a time when bone-grafting was regarded as a doubtful procedure. In these circumstances the attitude was probably justified because in many situations non-union would have diminished function to a greater extent than mal-occlusion, which could be remedied to some extent. The method, however, fell far short of the ideal and tended, quite naturally, to fall from favour as the success of the bone-graft became established.

The necessity or even ability to restore the bite depends clearly on the number of teeth present and their disposition.

The rule to be generally observed is that the correct relationship of the lower to the upper teeth should be restored in all cases in which this can be accurately gauged.

\section{Splinting.}

JAW BANDAGE. It is rare in these cases that a jaw bandage will give sufficient support but it has been found useful, however, as a supplementary measure. Its utility depends a good deal upon the method of construction. A good 
pattern used at the King George Hospital incorporated an upward pull with elastic traction.

Inter-dental wiring has been referred to previously. It may be applicable to the simpler cases or as a temporary means of fixation, but its use as a routine measure will be found impossible in the type of case under survey.

TIME. Some form of internal splint should be constructed and applied as soon as possible. The nature of the damage inflicted is an added reason for early action. A great number of war fractures of the mandible do not exhibit clean-cut fracture surfaces or loss of bone but rather a condition of comminution of varying degree.

The fragments between the main bone ends may be loosely attached and their separation may be undertaken in the mistaken idea that they are useless.

Early splinting is more than ever essential in cases of this kind to prevent recurrent traumatic hyperæmia which determines decalcification of the bone fragments and may lead to their eventual loss as sequestra.

There is no doubt that neglect to splint early and effectually is responsible for many cases of non-union.

TYPES. To take impressions in some of these cases an anæsthetic will be necessary and even then may be a matter of difficulty, particularly if any amount of time has elapsed since the receipt of injury.

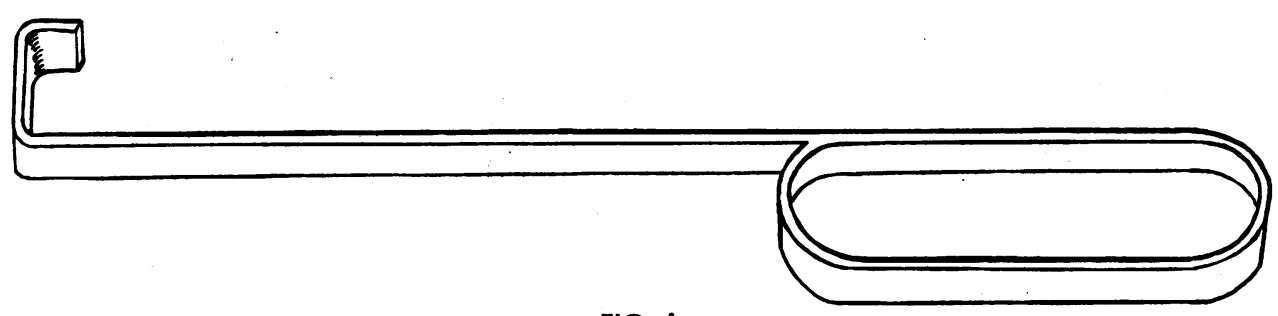

FIG. I.

The mandibular tractor, illustrated in Fig. I, will be found of use in maintaining traction on the lower jaw, thus enabling the dental surgeon to obtain easier access for tray and modelling compound. The hook end is covered by rubber tubing and the impression is taken with the tractor in situ, the tray being notched for the reception of the shaft.

Splints should be of simple construction and conform, as far as possible, to standardised patterns.

In the Inter-Dental type the splint affects the lower jaw alone and should be used wherever possible. It avoids fixation of the mandible and allows movement, thereby contributing to the comfort of the patient and the maintenance of muscular nutrition. They are usually cast in metal and are of two varieties:

1. Cap (Fig. 2). Method of fixation of flange is also illustrated; the occlusal services of the teeth are covered or left free. (Open Cap.).

2. Band and Bar. (Fig. 3). In the illustration are included types of flange which can be adapted to the bar as occasion may demand. One of these flanges is shown in position in photograph (Fig. 4 Art Plate). 


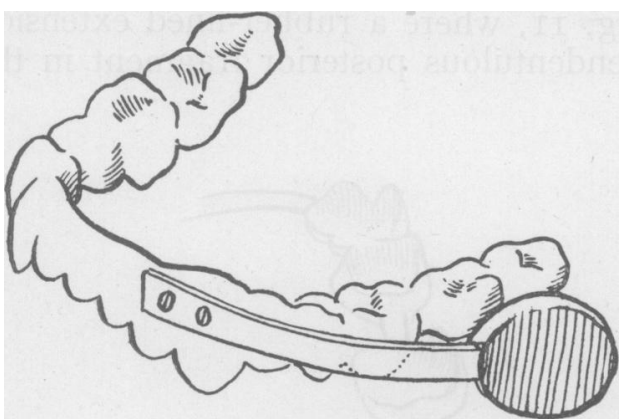

FIG. 2

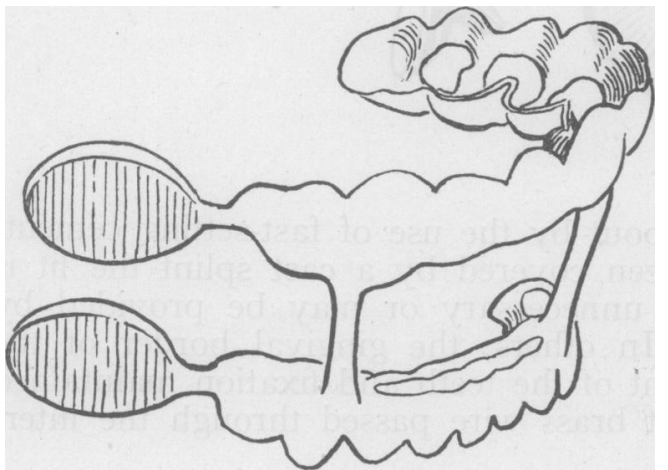

FIG. 5 .

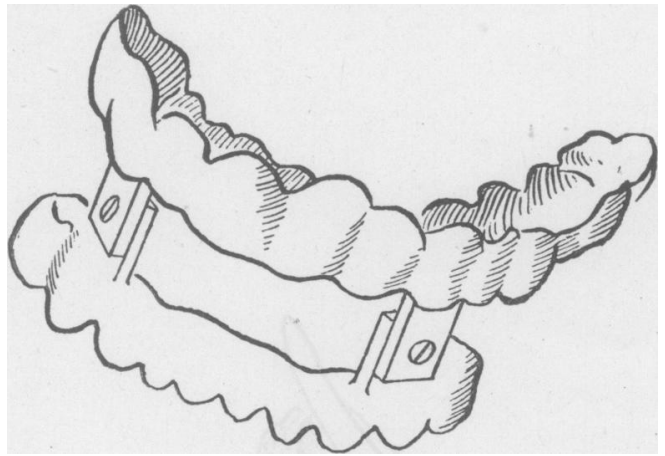

FIG. 9.

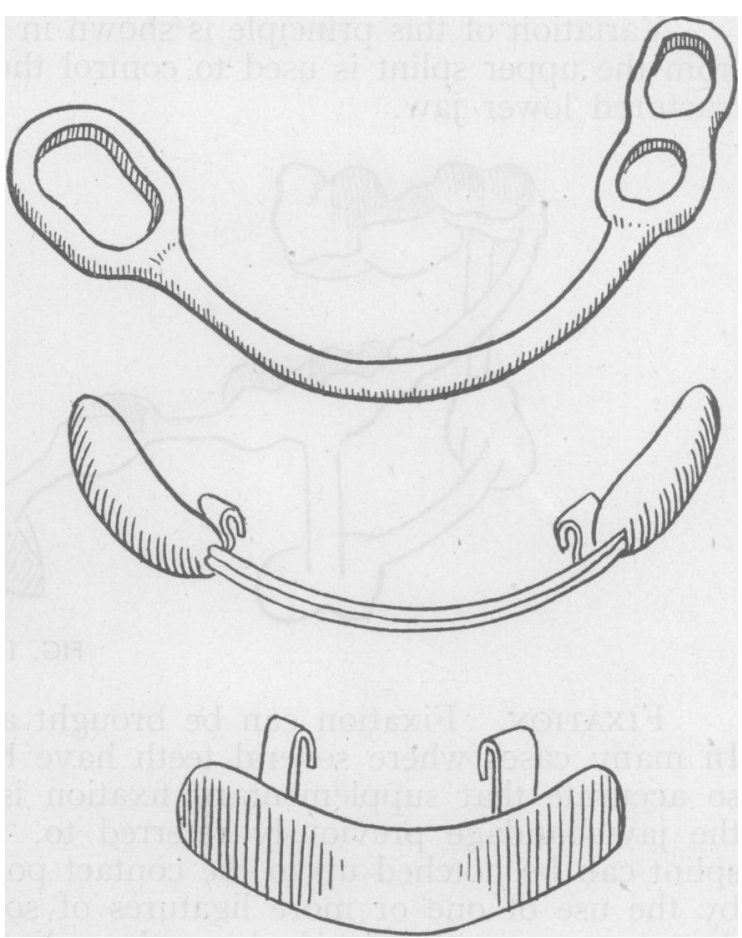

FIG. 3.

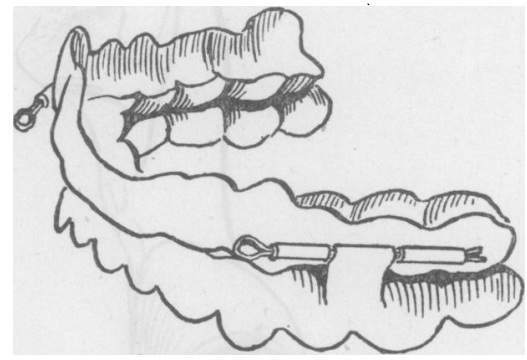

FIG. 10 .

MAXILlo-MANDIBULAR. In this type the mandible is splinted against the upper jaw. The open bite position referred to can frequently be adopted with advantage as shown in Fig. 5. Flanges shown are adapted to maintain contour during the process of healing or in the course of reconstruction. Splints in position are shown in Figs. 6, 7 and 8 (Art Plate).

Wherever possible the splints for upper and lower jaws should be detachable one from the other so that movement can be practised and the condition of the fragments reviewed from time to time. Fig. 9 illustrates such a splint adjusted in the open-bite position and separable by releasing the screws which lock the splints together. Another method of detachment is shown in Fig. Io, the splint here being adapted in the closed bite position. 
Variation of this principle is shown in Fig. II, where a rubber-lined extension from the upper splint is used to control the endentulous posterior fragment in the fractured lower jaw.

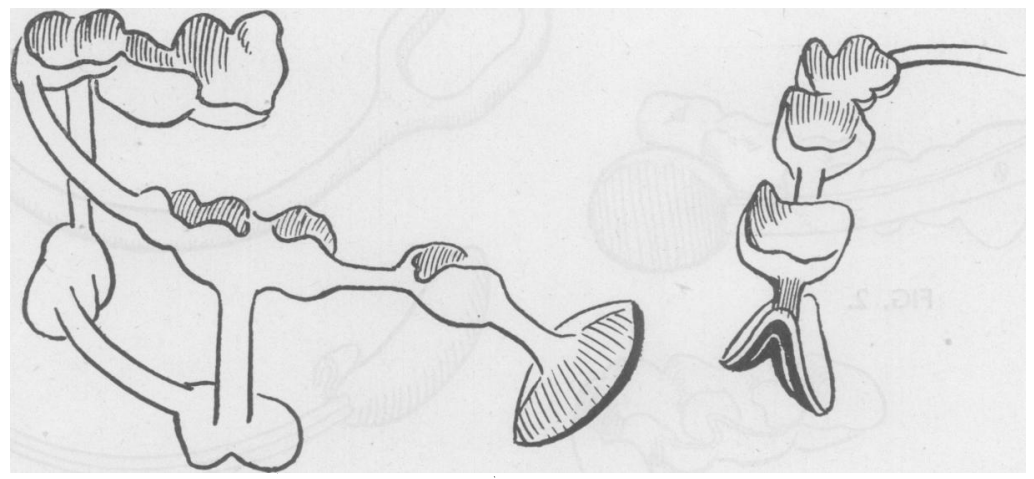

FIG. II.

Fixation. Fixation can be brought about by the use of fast-setting cement. In many cases where several teeth have been covered by a cast splint the fit is so accurate that supplementary fixation is unnecessary or may be provided by the jaw bandage previously referred to. In others, the gingival border of the splint can be notched up to the contact point of the teeth and fixation maintained by the use of one or more ligatures of soft brass wire passed through the interdental spaces and twisted above the splint.

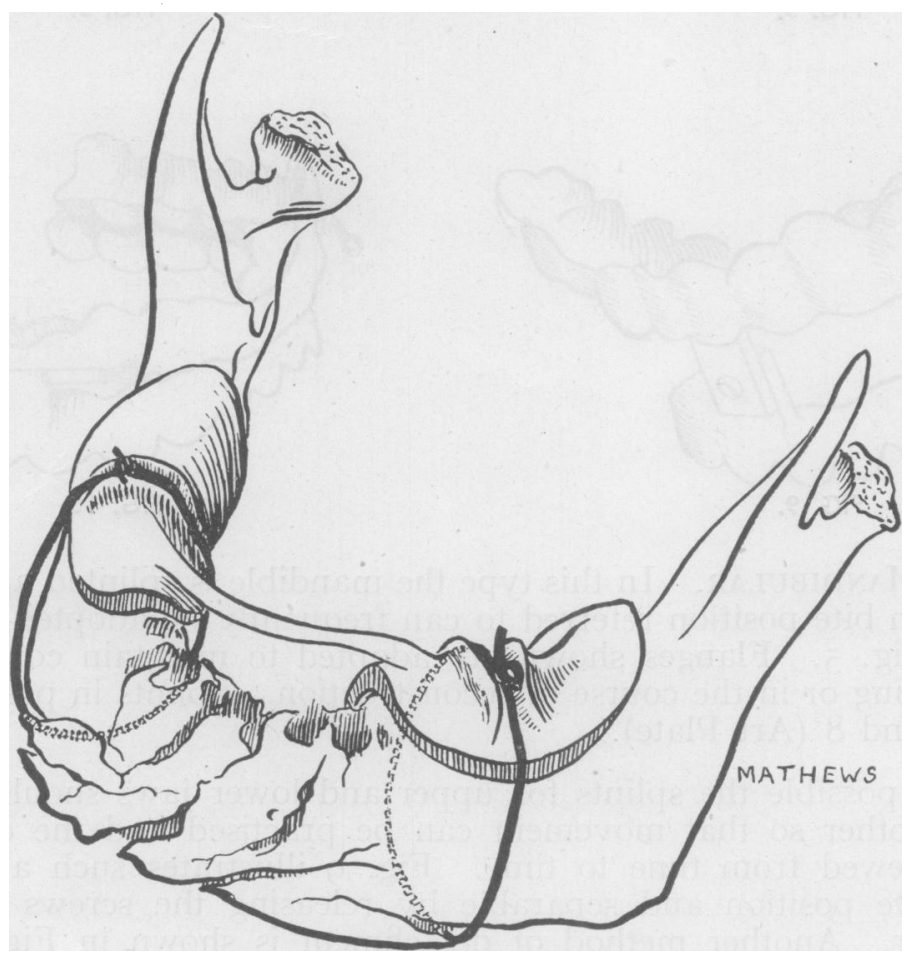

FIG. 12. 
ART PLATE.

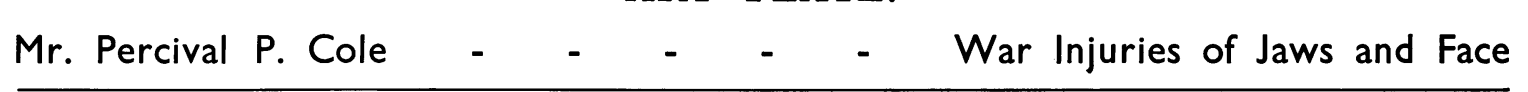

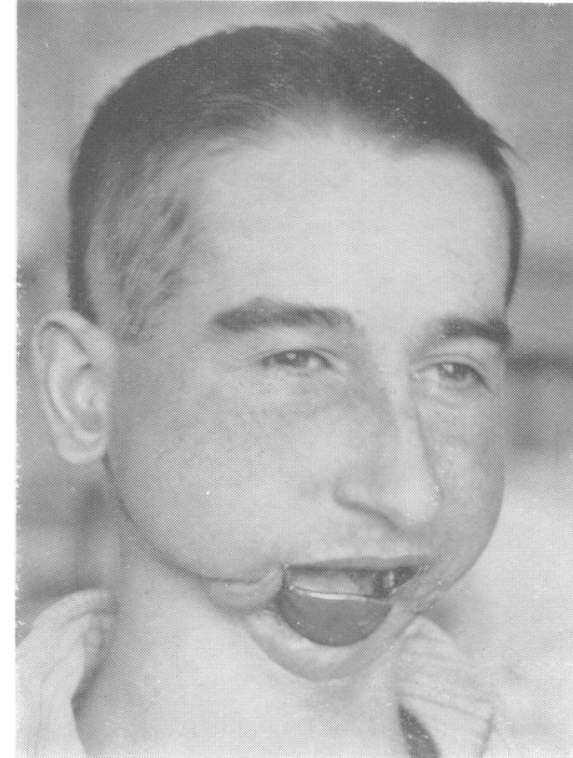

FIG. 4.

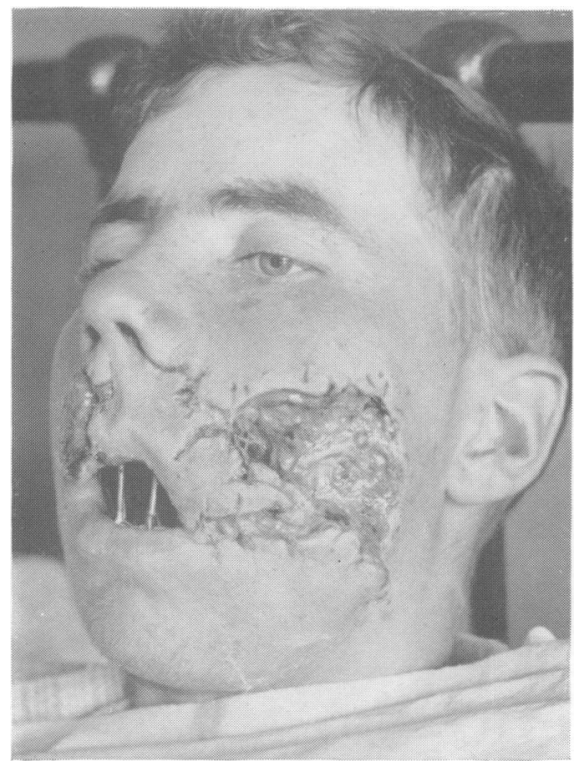

FIG. 7.

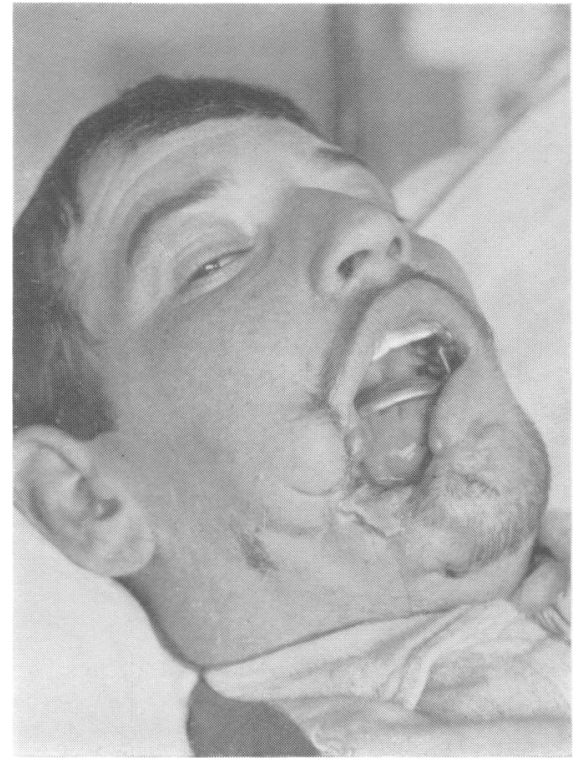

FIG. 6.

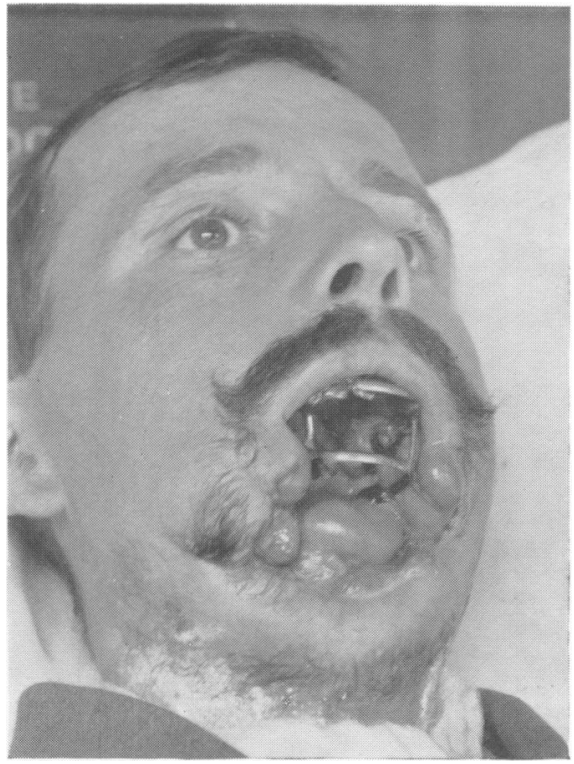

FIG. 8. 
ART PLATE.

Mr. Percival P. Cole $\quad-\quad-\quad-\quad-\quad-\quad-\quad$ War Injuries of Jaws and Face

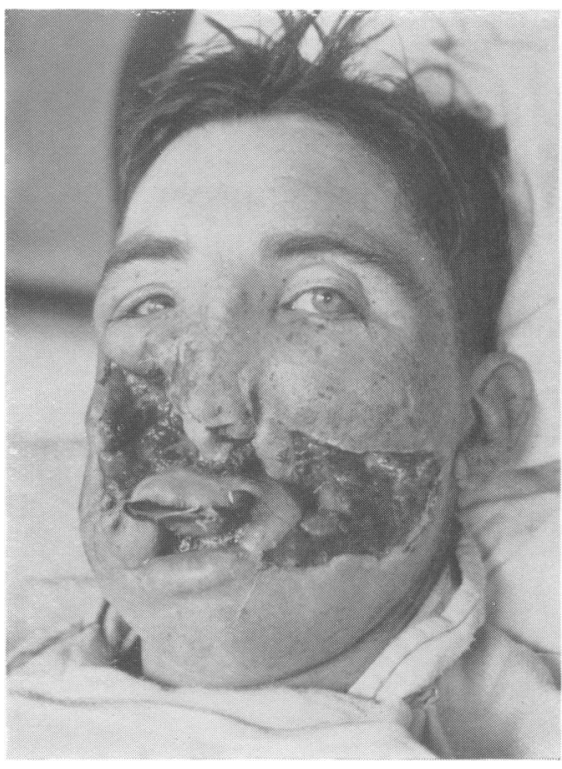

FIG. 13.

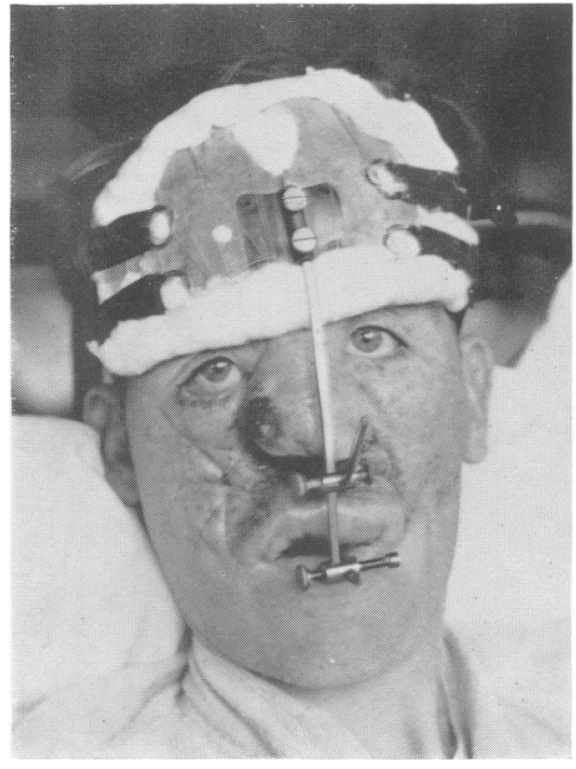

FIG. 14.

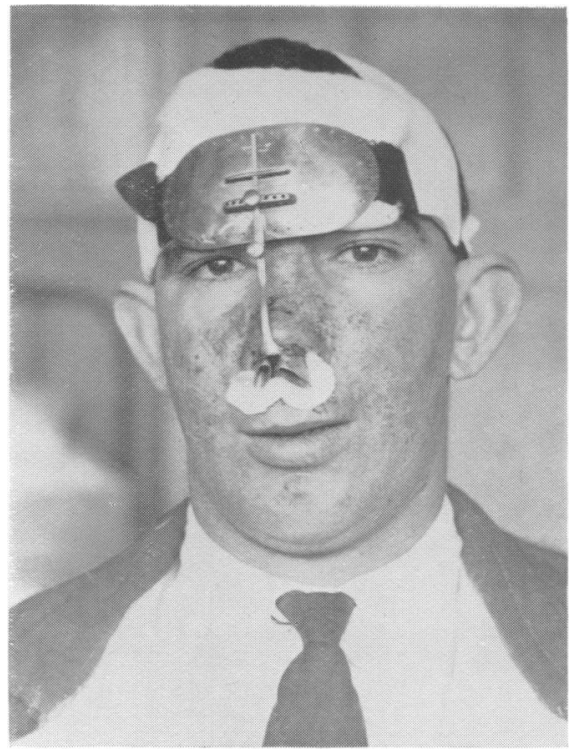

FIG. 15. 
The ability to discard cement is a point of practical value, for the removal of splints so fixed is often a laborious and lengthy task.

A further method of fixation is by circumferential wiring as illustrated in Fig. I2. This method is of use in cases in which the teeth in the lower jaw are either absent or afford inadequate hold and in cases in which the tendency to displacement is so great that cement fixation proves inadequate.

Circumferential wiring has been frequently employed by me not only for war injuries but,in civil practice. In only a very small percentage of cases has there been any swelling or pain and that of a purely transient nature.

Suspension to Fixed Apparatus Encircling or Capping the Head. The head can be employed with advantage as a fixed point in cases where the upper jaw has sustained severe damage leading to fragmentation and gross mobility. The same method can be employed in the adaptation of temporary prosthetic apparatus to maintain contour of the soft parts where considerable loss of bone has occurred. (Figs. I3, I4 and I5 Art Plate).

\section{Value of the open bite.}

The closed bite position is that ordinarily advocated for splinting. The open bite position can be employed consistently or be reserved for cases where its use is particularly indicated.

The incidence of trismus due to cicatricial contraction is not known because comprehensive figures are not available. One centre, however, reporting on 200 cases of injuries to the face and jaws stated that false trismus, or limitation of mouth opening, occurred in 66 out of the series and in 25 was definitely associated with fracture of the mandible. That these were not particularly serious cases is indicated by the fact that only II cases required plastic operation of any kind and of these eleven, three required mere adjustment of the red margin of the lip.

In the case of a cicatrizing wound threatening the movements of any particular joint it is the surgeon's endeavour and, indeed, his duty to maintain the joint in that position which will most effectually conserve the movement which is threatened. It follows that it is not only logical but incumbent on the surgeon and dental surgeon to prevent such limitation by maintaining the jaws in a position of open bite.

In the course of reconstruction with the mouth in the open bite position and flange properly adapted all tendency to limit the opening of the mouth will be avoided and the integrity of the buccal sulcus will be compulsorily respected.

With the mouth closed, tissues may be approximated without undue difficulty, but without regard to these essential requirements. There will be a temptation to choose the easy way and the result may well be a fair exterior that conceals a functional failure. Subject to certain technical safeguards, the difficulty, urged by some, of ensuring correct occlusion in the open bite position is an imaginary one.

\section{Buccal sulcus.}

The value of the buccal sulcus as a functional asset will be endorsed by every dental surgeon. The ability to adapt satisfactory dentures depends upon its integrity which will be threatened in one way or another during the course of treatment. The mucous membrane or its substitute may be reflected from the bone too near the summit of the alveolar ridge. The depth of the sulcus may be actually diminished, or its potential depth lessened, by tissues whose rigidity resists displacement. The ill effects that may follow the untimely extraction of numerous teeth in the damaged area has been cited in this connection. The benefit conferred 
by the employment of a properly adjusted flange in forcing the surgeon to allow full measure in the restoration of soft parts has been emphasised.

From the beginning and at every stage the maintenance of the buccal sulcus should be an ever present consideration. It is fortunate that restoration can be effected by plastic operation specially devised to this end. The advantage attaching to such a procedure will only be unmixed if it is reserved for cases where the occurrence is inevitable or where preventive measures have failed. Few are capable of restoring the buccal sulcus with any degree of certainty. Its maintenance in the course of treatment can be secured by the many.

\section{Diet scales.}

During the course of convalescence the ability to eat normal diet will be considerably helped by grading of the diet to accord with the degree of power existing in various stages. As in the last war, it will be found that four grades of diet will suffice to cover all gradations that present. The dietary should be tabulated in four scales and promotion from a lower to a higher grade should only be made when the patient has demonstrated his capacity.

The diet scale should be rigidly adhered to and this will be facilitated by grouping patients at table so that all on a particular scale are seated together. Catering arrangements are made easier and patients are not tempted to experiment with articles of diet which are really beyond their ability.

\section{Permanent prostheses.}

These may be considered under two heads:

(a) Dental, which will include the manufacture and adaptation of ordinary dentures or more complicated appliances of the obturator form to replace the bony scaffolding that has been lost and to maintain contour of soft tissues.

(b) Prosthetic apparatus-exclusively cosmetic in application and destined to replace large loss of surface tissues in order that the patient may not be conspicuous in ordinary daily contacts. These are made of light metal, aluminium or duralumin, the surface being painted to tone with the colour of the parts to which attachment is made. Other material used is of a plastic nature and consists largely of a gelatine base. Prostheses executed in this material can be very artistic and so natural as almost to escape detection in ordinary circumstances.

\section{Specialised Procedures to deal with Defects, either inevitable or resulting from faulty Treatment.}

\section{r. Non-union.}

Non-union may be inevitable owing to the amount of bone lost or may occur without loss of bone. Actually, loss of bone does not necessarily determine nonunion. The two essentials for union are the presence of a continuous hæmatoma and the exercise of adequate immobilisation. It is certain that the conditions necessary for union have been present in many cases where union has failed. Apart from unwarrantable interference the only cause has been the failure of early and adequate immobilisation.

Figures from three centres during the last war showed that non-union occurred in over I2 per cent. of all cases of fractured mandible. The incidence can be diminished by the elimination of defective treatment as a causal factor.

The attainment of union is undoubtedly important so far as it involves a functional demand. There is, however, no academic virtue in union apart from this and therefore the ultimate and only test should be a functional one-in the case of the mandible the patient's ability to masticate ordinary foods. That non-union 
used in the strict sense of the term is not incompatible with perfect function is as certain as that in some cases of obviously sound bony union the ability to masticate hard foodstuffs is denied.

Functional disability varies according to the site of fracture. In the ascending ramus the nearer the fracture to the condyle the less is the disability. Complete loss of ascending ramus if properly treated leads to no appreciable disability.

In the horizontal ramus disability increases as the symphysis is approached. Generally, if both masseters maintain attachment to one fragment disability is slight.

The decision to treat by operation will depend upon the degree of functionai disability and the estimated possibility of improvement.

Treatment of non-union. Wiring will be applicable to the few cases in which non-union has occurred without loss of substance and possibly even with some degree of overlap.

Bone-grafting. Generally speaking, restoration of soft parts should be completed before a bone-grafting operation is undertaken. Moreover, with a view to the elimination of latent infection a period of at least three months should elapse from the time that sound healing has been verified. The nature of the case will suggest that non-union may result and treatment will be devised from the beginning with this possibility or certainty in view. Any plastic operation must satisfy two essential requirements. Adhesions of skin scars to the bone in the immediate neighbourhood of the fracture must be prevented or remedied. A well-nourished pliable bed must be secured of a capacity sufficient to surround and enclose the graft without undue tension on the surface tissues when sutured in place over it. In any readjustment the topography of the tissues must be scrupulously observed. Buccal must be united to buccal tissues and lingual to lingual so that bony extension to the point of continuity can be envisaged between them. The separation of skin from bone and the determination of definite buccal and lingual strata has been conveniently and surely effected by the insertion of decalcified bone.

The success of bone-grafting for non-union has been established. Operative details cannot be given but three types are distinguishable:

(1) Pedicled Bone Graft (mandible).

(2) Free Bone Graft (crest of ilium, rib, tibia).

(3) Osteo-Periosteal.

\section{Mal-occlusion.}

Mal-occlusion may be present at a stage when union has not been consolidated. Reduction délayed for reasons justifiable or otherwise cannot be effected without resort to traction methods or direct surgical intervention. It is surprising how quickly resistance to reduction is developed. Traction methods may be employed but are slow and laborious. ' In this category, as in that where union is so firm that traction methods must fail, surgical measures directed to secure immediate reduction can be utilised with assurance of success. My dental colleague in the last war summed the matter up in these words: "I have never yet had to resort to any form of orthodontic appliance, surgical treatment achieving.in half an hour results that orthodontic treatment would take weeks, in some cases months, to accomplish."

3. Restoration by readjustment or reconstruction of the cheek, lips or chin.

Functional considerations demand that the amount of new tissue introduced must be sufficient to compensate for tissue lost and the encroachment by fibrosis on tissues remaining, either by the formation of scar tissue or by the diminution of their elasticity or by both. 
This amount is the measure of the operative loss which must always be greater than the actual loss.

Owing to these factors not capable of visual record, the magnitude of operation necessary is frequently far greater than might be suggested by an untutored survey of the deformity presented.

It is beyond the scope of this contribution to deal with the problems encountered and the methods employed. An enormous literature has grown up and great progress has been made in plastic surgery since the last war. Basic principles, however, remain unchanged and the recital of those outstandingly applicable to this site may serve a useful purpose:

1. Co-operation of dental and surgical expert is essential from the beginning.

2. The result will be largely influenced by the plan of treatment jointly evolved.

3. A flap with raw surface uncovered will shrink and must not be used.

4. The cheek and lips for plastic purposes consist of two layers. Tissue for their reparation can be of different extent and derived from different sources.

5. Skin forms an admirable substitute for mucous membrane.

6. Contraction occurs towards the more fixed point. The method known as "bringing the parts together" is particularly unsuitable in the presence of such mobile and easily distorted features as the angle of the mouth, lips and lower lid.

7. The open bite position and suitable flanges can frequently be used with advantage.

8. The epilatory effect of X-rays, particularly low voltage therapy, can be safely and effectually employed to extend the use of hair-bearing flaps to hairless areas.

4. Parotid fistula occurs in two forms:

(a) Fistula of the gland;

(b) Fistula of the duct.

Fistula of the gland is of relatively minor importance because healing either occurs spontaneously or can be induced by exposing the area to a suitable dose of X-rays.

Fistula of the duct can only be treated by operative measures, details of which cannot be dealt with here.

\section{Supplementary Services.}

I. X-ray diagnostic. 'It is unnecessary to stress the importance of an efficient $\mathrm{X}$-ray diagnostic plant. In many cases stereoscopic views are almost essential to obtain a correct estimate of the condition present. Equipment should include a portable apparatus.

2. Radiotherapy. X-ray and radium can usefully be employed in the treatment of such conditions as keloid, which may be very disfiguring. The epilatory effect of irradiation has been previously referred to. The success of this method has been amply demonstrated by the follow-up of flaps so treated over a number of years.

3. Physiotherapy. The physiotherapeutic department can offer valuable assistance in the way of ultra-violet and infra-red radiations, and massage, too, can be frequently employed with beneficial results. 
Notes on Anæsthesia for Facio-maxillary Surgery.

By WILLIAM W. MUSHIN, M.B., M.R.C.S., D.A.

(Hon. Ancesthetist, Central London Ear, Nose and Throat Hospital, Seamen's Hospital and Royal Dental Hospital; Ancesthetist, E.M.S.)

\section{PRINCIPLES UNDERLYING TECHNIQUE.}

I. Agent of Choice is Nitrous Oxide and OXygen. because, (a) operation may be long,

(b) patient may be shocked if trauma is recent,

(c) great depth of anæsthesia not required,

(d) cough reflex required immediately on completion.

(N.B.-Sufficient oxygen and premedication has killed the old bogy of capillary oozing with $\mathrm{N}_{2} \mathrm{O} / \mathrm{O}_{2}$ ).

2. ANASTHETIST AND HIS APPARATUS MUST BE OUT OF THE WAY.

Hence great value of endo-tracheal method used with a modern machine.

3. Aspiration OF BLOOD by PATIENT MUST BE PREVENTED.

by (a) pharyngeal pack of vaselined gauze, or inflatable cuff on tube (advantage of inhalational over insufflation method),

(b) suction-a necessity,

(c) rapid return of cough reflex.

4. Suitable AND SUFFicient PREMEdication

to (a) enable nitrous oxide and oxygen to be used without adjuvant,

(b) allow rapid return of cough reflex on withdrawal of gas,

(c) give prolonged sedation after operation with minimal disturbance of operation area.

In my opinion full doses of omnopon and scopolamine are best.

This also produces sufficient drying of mouth and pharynx.

N.B.-Caution in premedicating shocked patients.

5. Perfect airway must be maintained

by oral or nasal endotracheal tube. If neither of these routes is available then via laryngotomy or tracheotomy.

6. EXPLOSION RISK.

Diathermy often used.

In this event, the only admissible adjuvant to $\mathrm{N}_{2} \mathrm{O} / \mathrm{O}_{2}$ is Chloroform.

\section{TYPES OF CASES.}

I. Simple PROCEDURES, e.g., dressings or impression taking.

Moderate dose of omnopon/scopolamine followed by short acting intravenous barbiturate (e.g., pentothal), if necessary by repeated doses or continuously.

Caution: maintain good airway by (a) position of head and jaw, or (b) naso-pharyngeal tube. 
2. MORE EXTENSIVE REPAIRS.

A. Nose or mouth is available for tube.

(a) Full premedication with omnopon/scopolamine, e.g., omn. gr. 2/3 scopol. gr. I/I50 for adult.

(b) Endo-tracheal inhalational nitrous oxide/oxygen via large bore, well lubricated, soft rubber tube, passed blindly through nose, or by direct vision via mouth.

(c) Inflatable cuff on tube, or vaselined gauze pack around tube, to prevent leakage of blood, or air (would dilute mixture and upset anæsthetic).

(d) Keep patient adequately oxygenated, and use machine capable of accurate fractional rebreathing (e.g., McKesson). Minimum rebreathing for necessary ventilation to get freedom from oozing.

(e) Before removing packing or deflating cuff, remove blood in mouth by suction. Remove tube only when cough reflex is returning.

Chief advantages of endotracheal method:-

I. No respiratory obstruction.

2. Respiration under control.

3. No danger of blood aspiration.

4. Operation field is clear of anæsthetic impedimenta.

B. Both mouth and nose are in field of operation.

May have to do preliminary laryngotomy or tracheotomy (e.g., under pentothal). Then pass tube with inflatable cuff via this opening and administer $\mathrm{N}_{2} \mathrm{O} / \mathrm{O}_{2}$. 